\title{
Biography of Professor Nicolaou: a journey to the extremes of molecular complexity
}

\author{
The Journal of Antibiotics (2018) 71, 149-150; doi:10.1038/ja.2017.144
}

$\mathrm{O}$ ne of the most gratifying progresses in recent history has been the advent of therapeutic agents that have extended our life span and improved our quality of life. The tremendous progress achieved in therapeutics is rooted in enabling synthetic methodologies and strategies to assemble ever more sophisticated and effective molecules. It is thus a particular pleasure to have an issue of the Journal of Antibiotics that celebrates a legendary practitioner in this area of synthetic chemistry, going from the fundamental development of methodologies and strategies to the extremes of molecular complexity. KC Nicolaou has made extraordinary contributions to the art and science of total synthesis and stands as a leader in the synthesis of complex molecules.

KC Nicolaou was born in Karavas, on the northern coast of Cyprus, where he grew up amidst rolling hills and orchards, finishing his high school education in Nicosia at the Pancyprian gymnasium, an institution that counts several former presidents of Cyprus as well as a Nobel laureate amongst its former students. In 1964, he emigrated to England where he spent two years learning English and preparing to enter university while selling fish and chips on the side to supplement his means. He attended the University of London where he studied chemistry (B.Sc., 1969, Bedford College, First Class Honours) and moved to University College London for his Ph.D. which he completed in three years under the supervision of professors F Sondheimer and PJ Garratt. In 1972, he crossed the Atlantic to the United States and completed postdoctoral appointments at Columbia University (19721973, Professor TJ Katz) and Harvard University (1973-1976, Professor EJ Corey), where he discovered the intricacies of total synthesis and its fertility as a testing ground for new methodologies. There he also fostered deep friendships with some of his peers such as Masakatsu Shibasaki which seeded a deep connection with researchers in Japan. He started his independent career at the University of Pennsylvania, where he rose through the ranks to become the Rhodes-Thompson Professor of Chemistry. In 1989, he accepted joint appointments at the University of California, San Diego and The Scripps Research Institute, where he was the Chairman of the Department of Chemistry and held the Darlene Shiley Chair in Chemistry and the Aline W and L Skaggs Professorship in Chemical Biology. He contributed tremendously to the transformation of The Scripps Research Institute from an immunology-focused institute to the chemical biology power house it is today. From 2005 to 2011, he was allured by the rise of chemical science in Singapore and spent part of his time directing the Chemical Synthesis Laboratory at ICES-A ${ }^{\star}$ STAR. In 2013, he moved to Rice university where he currently holds the Harry C and Olga K Wiess Chair to focus on the application of total synthesis to the treatment of cancer.
Professor Nicolaou's achievements in total synthesis are admirable for the complexity and diversity of the targets, pushing the boundaries of what can be accessed through chemical synthesis with numerous 'first syntheses'. Examples of his field-shaping achievements are his contributions in the area of oligosaccharide natural products, macrolides, enediynes, taxoids, epothilones, polyether marine neurotoxins, and biomimetic approaches to complex molecules, all of which are still topical and exciting areas of research within the domain of chemical synthesis. More specifically, his strategies and tactics are often used by many who follow him in the pursuit of the same or structurally similar target molecules. A first synthesis blazes the trail for subsequent work and provides critical insight into possible disconnection as well as endgame oxidation/ protecting group strategies. Nicolaou's achievements have shaped and propelled the art of total synthesis to its highest levels of sophistication and intricacy. From all his numerous accomplishments, the total syntheses of the following molecules represent perhaps his highest achievements in medicinally relevant molecules: amphotericin B (antifungal agent, 1987), calicheamicin $\gamma 1 \mathrm{II}$ (anticancer drug, 1992), rapamycin (anticancer and immunosuppressive drug, 1993), taxol (top-selling anticancer drug, 1994), zaragozic acid A (cholesterol-lowering agent, 1994), brevetoxins B and A (marine neurotoxins, 1995 and 1998), epothilones A and B (anticancer drugs currently in clinical trials, 1997), vancomycin (antibiotic of last resort, 1999), the CP molecules (cholesterol-lowering agent, 1999), azaspiracids-1, -2 and -3 (marine neurotoxins, 2004-2006), platensimycin (antibiotic, 2006), haplophytine (insecticide, 2009) and shishijimicin A (cytotoxic, 2015). Amphotericin B, calicheamicin $\gamma 1 \mathrm{I}$, rapamycin, taxol, the epothilones, and vancomycin are all clinical agents. Among these, taxol serves as his most celebrated and widely recognized triumph. Indeed, considered as the 'holy grail' of synthesis in the late 1980s and early 1990s, this extraordinary molecule stands as the quintessential symbol of all natural product molecular complexity, and its total synthesis as the single most important milestone of complex molecular construction in recent decades. The total synthesis of the highly complex molecule of the antitumor agent calicheamicin $\gamma 1 \mathrm{II}$ was accompanied by a series of breakthroughs in new synthetic strategies and technologies, and numerous discoveries and inventions in chemical biology, particularly in the areas of DNA recognition and cleavage, and cancer chemotherapy. Representing the first example of an antibody drug conjugate (ADC), calicheamicin $\gamma 1 \mathrm{I}$ was introduced as a clinical agent marketed by American Home Products under the name of Mylotarg for the treatment of leukemia. The field of Nicolaou's investigations in the epothilone area marked the beginning 
of an important new trend in chemical synthesis, combinatorial chemistry. Split and mix synthesis were enabled by the introduction of the radiofrequency or 2D barcode encoding. Technologies that were applied to the synthesis of large natural product-like libraries for chemical biology investigation. His work on potent cytotoxics that can be used in ADC has delivered chemical syntheses for other potent yet scarce enediynes: Shishijimicin A, the most potent cytotoxic of the enediynes (with subpicomolar $\mathrm{IC}_{50}$ ); Uncialamycin, for which a highyielding chemical synthesis was developped. The polyether marine toxin exemplified by the brevetoxins and related molecules such as ciguatoxin are potent neurotoxins that cause severe food poisoning but are also symbols of molecular complexity.

Total synthesis at the extreme of molecular complexity has often been compared to the conquest of the highest peaks. But for $\mathrm{KC}$ Nicolaou, it is more akin to a battle and a journey that requires resourcefulness, creativity and stamina. The inherent challenges of a first total synthesis of a complex molecule are such that it rarely works as originally planned. The unforeseen obstacles of intricate molecules demand agility; the decision to push ahead or retreat and redesign when facing an obstacle in the labyrinth of synthetic pathways are at the frontier between art, flair and science. Amidst the punctual battles, there is also a journey filled with opportunities as echoed in the poem of by CP Cavafy 'Ithaca' which KC Nicolaou chose for his introduction of the 'Classics in Total Synthesis' co-authored with E Sorensen. This is also echoed in his concluding remarks in an article recounting the story of the CP molecules 'The entire enterprise should be based on the premise of not only reaching the destination, but most importantly, collecting 'goods and wisdom' along the way. We wish for more targets like the CP molecules, so that they can challenge and sharpen the minds and skill of new 'Theseus'.' (Angew. Chem. Int. Ed. 2002, 2678).

Behind every great man, there is an even greater woman, and $\mathrm{KC}$ is the first to recognize the amazing contributions of his wife, Georgette, in enabling a fulfilled academic life and family life with four children and six grandchildren!

On a more personal note with the conflicts currently taking part in Middle East, not far from Cyprus, the incredible achievements of $\mathrm{KC}$ Nicolaou is an important reminder that success can arise from adversity. Cyprus witnessed frequent conflict between Greeks and Turks and the northern part of Cyprus where KC grew up was occupied by the Turkish army in 1974. KC never returned to his home town until the 21st century but proudly displayed his Greek heritage along his rise to the leader he is today.

For his scientific work, Professor Nicolaou has received numerous awards and honors, including the Humboldt Foundation US Senior Scientist Prize (Germany, 1987), the AC Cope Scholar Award, American Chemical Society (1987), the Award for Creative Work in Synthetic Organic Chemistry, American Chemical Society (1993), the Dr. Paul Janssen Prize for Creativity in Organic Synthesis, Janssen Research Foundation (1994), the Rhone-Poulenc Medal, Royal Society of Chemistry (UK, 1995), the William H Nichols Medal, New York Section-American Chemical Society (1996), the Inhoffen Medal, Gesellschaft fur Biotechnologische Forschung mbH (GBF) (Germany, 1996), the Ernest Guenther Award in the Chemistry of Natural Products, American Chemical Society, the Chemical Pioneer Award, American Institute of Chemists, the Linus Pauling Award, Oregon,
Portland, Puget Sound Sections-American Chemical Society, the Decoration of the Order of the Commander of Honor Medal (bestowed by the President of Greece, 1998), the Esselen Award for Chemistry in the Public Interest, American Chemical Society (1998), the Yamada Prize (Japan, 1999), the first Aspirin Prize for Solidarity through Chemistry (Spain, 1999), the Max Tishler Lecture Prize, Harvard University (2000), the Paul Karrer Gold Medal, Universitat Zurich (Switzerland, 2000), the Centenary Medal, Royal Society of Chemistry (UK, 2000-2001), the Ernst Schering Prize, Ernst Schering Research Foundation (Germany, 2001), the Nagoya Gold Medal of Organic Chemistry, Nagoya University (Japan, 2001), Tetrahedron Prize for Creativity in Organic Chemistry (2002), the ACS Nobel Laureate Signature Award for Graduate Education in Chemistry (2003), the Aristeio Bodossaki Prize (2004), the ACS A.C. Cope Award (2005) Auburn Section-American Chemical Society Auburn-G. M. Kosolapoff Award (2006), the Burkardt-Helferich Prize (2006), the ISHC Senior Award in Heterocyclic Chemistry (2007), the August-Wilhelm-von-Hofmann-Denkmünze Award (2008), and the Chandler Medal, Columbia University (2008), Lampousa Lifetime Achievement Award (Cypriot American Association, 2009), ACS Creativity in Molecular Design and Synthesis Award (New Jersey Section, 2012), The MAN of the Year Award (Cyprus, 2015), The Wolf Prize (2016).

KC Nicolaou is a Member of the New York Academy of Sciences (1987), Fellow of the American Academy of Arts and Sciences (1993), Member of the National Academy of Sciences (USA, 1996), Fellow of the American Association for the Advancement of Science (1999), Foreign Member, Academy of Athens (Greece, 2001), Honorary Fellow of the Indian Academy of Sciences (2007), Honorary Member of the Israel Chemical Society (2009), Member of the German Academy of Sciences Leopoldina (2009), Member of the American Philosophical Society (USA, 2011), Foreign Member of the Royal Society of London (UK, 2013), Member of the Academy of Medicine, Engineering \& Science of Texas (USA, 2013), Fellow of the National Academy of Inventors (USA, 2015) and holds 12 honorary degrees from universities around the world.

$\mathrm{He}$ is the author or co-author of nearly 800 scientific articles, reviews, and book chapters, 68 patents, and 5 books, including the popular Classics in Total Synthesis co-authored with his student Erik J Sorensen (1996 VCH), Classics in Total Synthesis II co-authored with his student Scott A. Snyder (2003, Wiley-VCH), Classics in Total Synthesis III co-authored with his student Jason S. Chen (2011, Wiley-VCH) and Molecules That Changed the World, co-authored with his research associate T Montagon (2008, Wiley-VCH). His dedication to chemical education also transpires through his training of more than 400 graduate students and postdoctoral fellows who hold some of the most important and influential positions in universities and companies world-wide, a training I cherished.

\section{CONFLICT OF INTEREST}

The authors declare no conflict of interest.

Nicolas Winssinger

Organic Chemistry, University of Geneva, Geneva, Switzerland 